\title{
Conception of comics dedicated to optics learning
}

Jacques Machemy, Bruno Bousquet

Jacques Machemy, Bruno Bousquet, "Conception of comics dedicated to optics learning," Proc. SPIE 9793, Education and Training in Optics and Photonics: ETOP 2015, 97931F (8 October 2015); doi: 10.1117/12.2223111

SPIE Event: Education and Training in Optics and Photonics: ETOP 2015, 2015, Bordeaux, France 


\title{
Conception of comics dedicated to optics' learning
}

\author{
Jacques Machemy ${ }^{\mathrm{a}}$, Bruno Bousquet*a \\ aUniversity of Bordeaux, 351 cours de la Libération, F - 33405 Talence, France
}

\begin{abstract}
Optics' teaching is commonly based on the use of lessons including several mathematical tools. For example, ray tracing can be described through matrix algebra, and interference and polarization can be supported by the use of complex numbers. Thus, the numerous mathematical descriptions included in the optics' lessons represent a real difficulty for students having insufficient skills in mathematics. Moreover, despite of very impressive optical effects one can observe in real life, e.g. rainbows, their description in optics' courses is often considered as too academic and boring, and finally not really exciting.

In this context, we have invented a new type of comics dedicated to optics' learning. Based on a dialogue between two imaginary characters, one considered as the young student and the other one as the old teacher, we have chosen to reduce the role of mathematics and to mix realistic and unrealistic elements in the drawing to complete the explanations faster. Starting from reflection and refraction, the Snell's laws then allow for describing natural phenomena such as mirage and rainbow as well as technical points such as light propagation into an optical fiber and the measurement of the refraction index.

The first volume presented here will be evaluated during the fall semester 2015 in different high schools and at university through a linked survey and the students will also get access to an online version while the following parts are in preparation.
\end{abstract}

Keywords: Education and training, Optics, Comics, Alternative learning resources

\section{INTRODUCTION}

Learning optics requires good skills in mathematics associated with strong abstraction ability $[1,2,3]$. As an example, ray tracing can be supported by matrix algebra and the students are expected to mentally visualize the conditions of real and virtual images formation. Other examples: the concept of interference involves waves and their relative phase, and is supported by the use of complex numbers; polarization is supported by the Jones' formalism based on both matrix algebra and complex numbers. Many other examples could be given and all of them illustrate the predominant role of mathematics in optics' learning.

However, these last years, it has been observed that students in high school and in the higher education system didn't feel confortable with many mathematical tools and physical models [2, 3, 4]. As a consequence, their motivation and then their ability to learn new physical concepts are reduced. Therefore, misconceptions are frequent in optics $[5,6,1$, 7]. Difficulties with manipulating complex numbers for example can be seen as an obstacle to calculate interference patterns or polarization states. It is worth pointing out that the required mathematical skills are not unknown by the students, but they are often insufficiently appropriated by them. Ideally, prerequisite should be consolidated before going on higher education programs but time is always missing for that and thus, new physical concepts are often built on fragile foundations.

In addition, young students do not consider learning science and further scientific careers as very exciting, and scientific education and training programs suffer from a general disaffection worldwide $[8,9,10,11]$. Indeed, if abstract concepts can still be taught nowadays at the master's level by using the same approaches as the one exploited in the past, introductory courses must be much more attractive.

*bruno.bousquet@u-bordeaux.fr

Education and Training in Optics and Photonics: ETOP 2015, edited by Eric Cormier, Laurent Sarger Proc. of SPIE Vol. 9793, 97931F · (c) 2015 SPIE, IEEE, OSA, ICO · doi: 10.1117/12.2223111 
In this context, we believe that mathematics-light course contents should be proposed to the youngest students in order to facilitate their access to higher education and to make sciences more attractive. Moreover, we believe that students can learn also and maybe even better from documents that have not a classical form. Some rare previous works exposed the pedagogical possibilities provided by graphic narratives (e.g. comics) (e.g.[12, 13,14]). Because they integrate images with text, viewing and reading graphic narratives stimulates both analytic and creative activity in the brain, a process that has been shown to enhance understanding [15]. Moreover, comics seem to be semiotic resources during learning [16], providing a link between theories and reality. Therefore, we think that comics could be interesting tools to enhance students' reflection and helping them to make inferences between mathematical concepts and physical phenomenon.

For these reasons we decided to design and realize comics dedicated to physics' learning. More precisely, we focused our first volume on geometrical optics since this is a key-course to transmit the taste to pursue studies in optics and photonics.

The aim of the project described in the present paper was to:

- $\quad$ Build comics dedicated to optics' learning

- Help the students' understanding by reducing mathematics

- Allow for young students fast access to the main concepts of geometrical optics

- Make the reader get interested in optics and feeling like going further

\section{COMICS: DESCRIPTION}

The first volume of comics presented here has been designed two years ago, based on the course of geometrical optics that is taught at the Institute of technology of the University of Bordeaux. The content is also treated at the high school level. Basically, it deals with the concepts of refraction and reflection and on a series of simple phenomena and applications of them, such as rainbow, mirage, light propagation inside an optical fiber, or the measurement of the refraction index. The present version is in French language.

Two characters were invented, far from realistic appearance, midway between humans and animals. The younger one is described as enthusiastic for learning but he doesn't feel comfortable with the mathematics, and he is frequently overwhelmed with abstract notions. Thus, any student learning optics and experiencing some difficulties can easily identify himself with him. The older character is presented as a wise person who knows many things and who behaves as the ideal teacher, namely very patient and enthusiastic to transmit all that he knows. Figure 1 illustrates these two characters while they are discussing about light ray propagation.

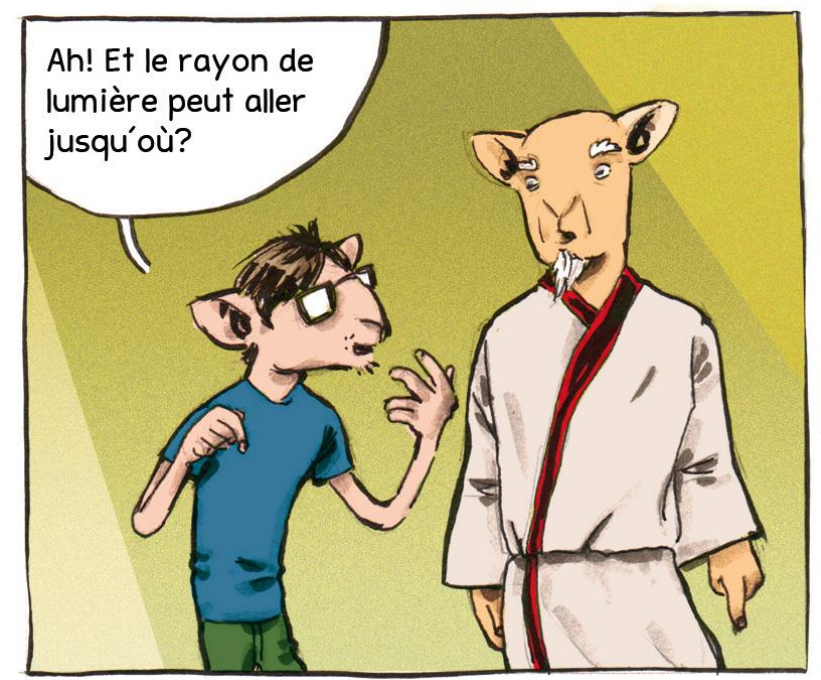

Figure 1. Presentation of the two imaginary characters of the comics, midway between humans and animals. 
It should be emphasized that only one single mathematical expression is given in this comic, namely the refraction Snell's law, which crashes to the younger character as displayed in Figure 2.

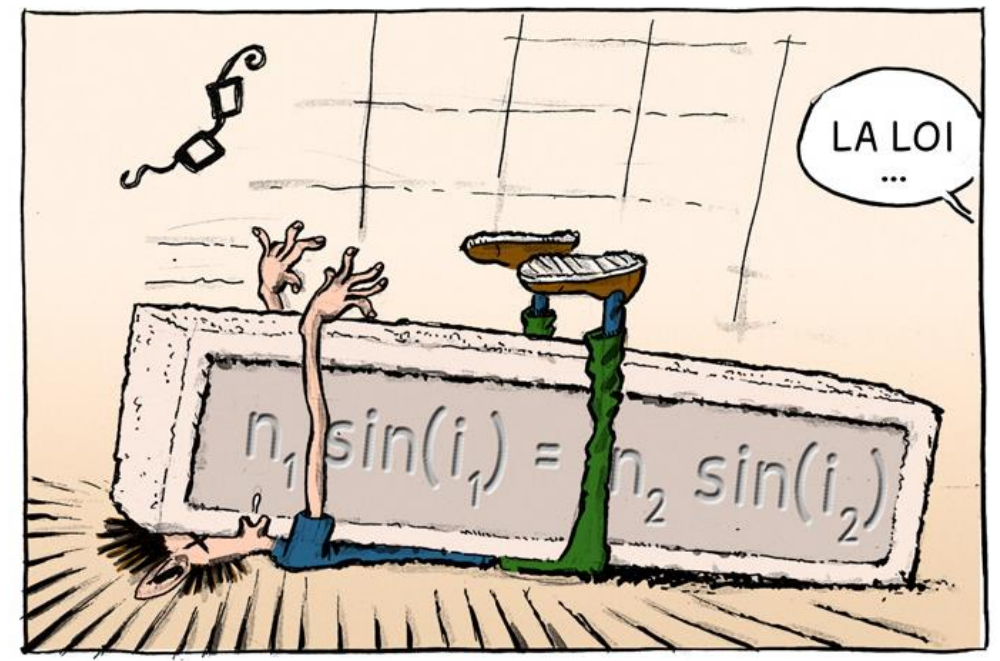

Figure 2. Presentation of the Snell's law, which crashes down to the floor and onto the younger character.

This presentation is voluntarily fast and fun in order to push the message that, at this moment, the most important is not to understand how the refraction Snell's law can be justified but how one can directly apply it and retrieve a series of results. In this way, this course doesn't emphasize the physical models but aims to quickly retrieve the main results, based on minimal mathematical descriptions.

The drawings also mix characters in interaction and graphic elements expected to help the reader understanding better the explanations. As an example, in the case of mirage, as displayed in Figure 3, a series of air layers are displayed with different colors to facilitate the understanding and a series of vertical dashed segments indicate the locations where the refraction Snell's law was applied. The result is a white ray changing its direction at each layer interface, until total reflection occurs.

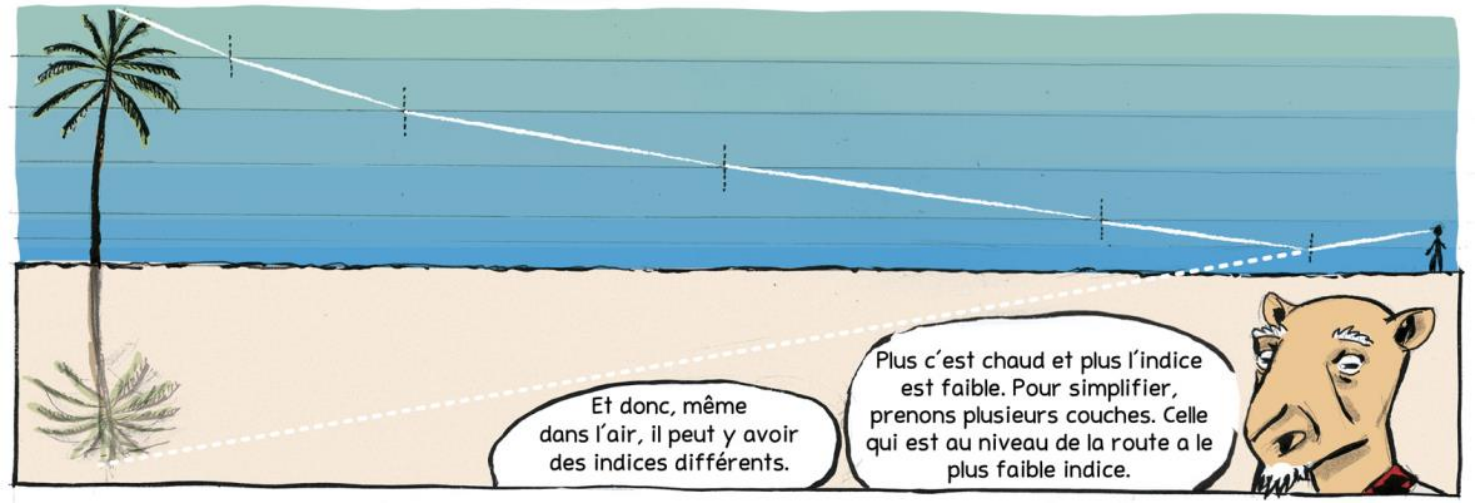

Figure 3. Model of mirage including a series of air layers with different refraction index and ray tracing inducing the mirage effect.

We also decided to mix very realistic objects with completely unrealistic ones in order to go faster and to simplify the explanations. Thus, the prism presented in Figure 4 is displayed in a very realistic way while the incoming light is provided by a kind of mini-sun holding a strange light gun. This allows presenting an incoming white ray characterized by a single angle of incidence when arriving onto the prism. A realistic scheme of this experiment would have necessitated much more efforts to properly describe how to prepare the incident light with the risk to be out of the main purpose at this point. And consequently, this simplistic representation of incident light helps to focus on the prism itself. 


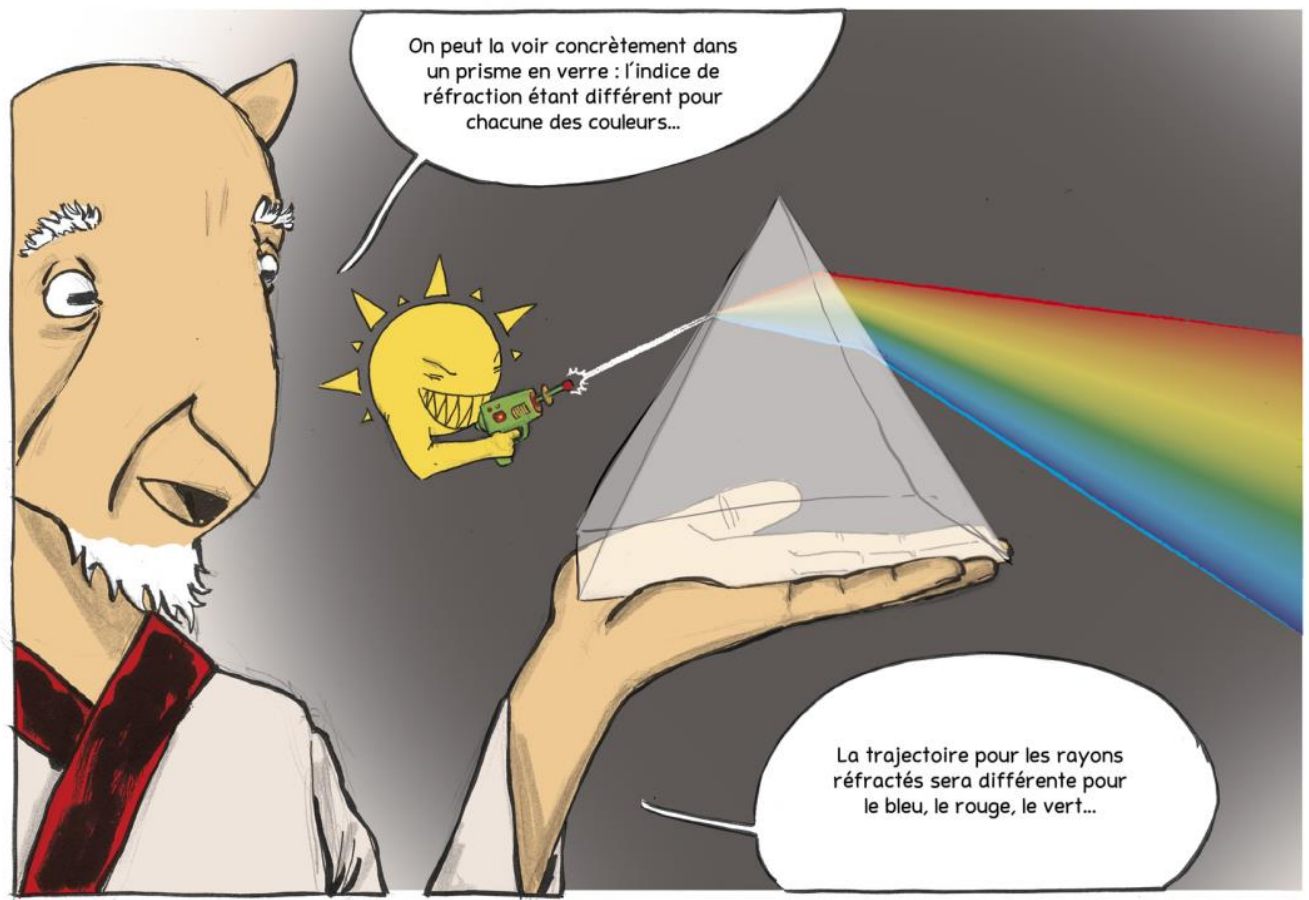

Figure 4. Light propagation trough a transparent prism mixing a very realistic prism and an unrealistic mini-sun holding a light gun

\section{FUTURE WORK}

We have described our strategy for editing a series of comics in order to offer an alternative support for optic's learning and we have illustrated this work via the first volume dedicated to geometrical optics and mainly focused on the Snell's laws. The next volume is already in progress and will address the questions of object-image pairs when light propagates through different media with plane or curved interfaces and with a special highlight on thin lenses and mirrors, which are key-components included in most of the optical instruments.

The first volume will be provided to several groups of students with a dedicated survey in order to evaluate the benefit of this new kind of learning resource. Furthermore, in addition to the paper version, a numerical version of these comics will be provided online.

\section{REFERENCES}

[1] Galili, I., and Hazan, A., "Learners' knowledge in optics: interpretation, structure and analysis," International Journal of Science Education, 22(1), 57-88 (2000).

[2] Maurines, L., "Geometrical Reasoning in Wave Situations: The case of light diffraction and coherent illumination optical imaging," International Journal of Science Education, 32(14), 1895-1926 (2009).

[3] McDermott, L. C., "Oersted medal lecture 2001:"Physics Education Research-the key to student learning"," American Journal of Physics, 69(11), 1127-1137 (2001).

[4] Weil-Barais, A., and Vergnaud, G., [Students' Conceptions in Physics and Mathematics: Biases and Helps] NorthHolland, (1990).

[5] Djanette, B., and Fouad, C., "Determination of University Students' Misconceptions about Light Using Concept Maps," Procedia - Social and Behavioral Sciences, 152(0), 582-589 (2014). 
[6] Galili, I., "Students' conceptual change in geometrical optics," International Journal of Science Education, 18(7), 847-868 (1996).

[7] Palacios, F. J. P., Cazorla, F. N., and Madrid, A. C., "Misconceptions on geometric optics and their association with relevant educational variables," International Journal of Science Education, 11(3), 273-286 (1989)

[8] Commission Européenne - Eurydice, [L'enseignement des sciences en Europe: politiques nationales, pratiques et recherche], Bruxelles(16 Novembre 2011).

[9] European Commission, [Europeans, Science and Technology ], (2009).

[10] Forsthuber, B., Motiejunaite, A., and de Almeida Coutinho, A. S., [Science Education in Europe: National Policies, Practices and Research] ERIC, (2011).

[11] Robine, F., "Réformer l'éducation scientifique : une prise de conscience mondiale," Revue internationale d'éducation de Sèvres [En ligne], 51, 1-9 (2009).

[12] Berkowitz, J., and Packer, T., [Heroes in the Classroom: Comic Books in Art Education] National Art Education Association, (2001).

[13] Green, M., "Teaching with Comics: A Course for Fourth-Year Medical Students," Journal of Medical Humanities, 34(4), 471-476 (2013).

[14] Guadamillas Gómez, M. V., "Reading, Speaking and Writing through Creative Resources: Comics in Second Language Teaching," Arab World English Journal, 5(4), 443 (2014).

[15] Mayer, R. E., and Sims, V. K., "For whom is a picture worth a thousand words? Extensions of a dual-coding theory of multimedia learning," Journal of Educational Psychology, 86(3), 389-401 (1994).

[16] Herbst, P., Chazan, D., Chen, C.-L., Chieu, V.-M., and Weiss, M., "Using comics-based representations of teaching, and technology, to bring practice to teacher education courses," ZDM, 43(1), 91-103 (2011). 